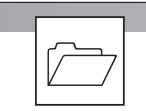

Endokrynologia Polska

DOI: 10.5603/EP.a2019.0039

Volume/Tom 71; Number/Numer 1/2020 ISSN 0423-104X

\title{
Two cases of pheochromocytoma in pregnancy: a multidisciplinary challenge
}

\author{
Grzegorz Chmielewski ${ }^{1}$, Agnieszka Walczyk², Aldona Kowalska ${ }^{2,3}$ \\ ${ }^{1}$ ESKULAP Student Scientific Organisation, Faculty of Medicine and Health Sciences, Jan Kochanowski University, Kielce, Poland \\ ${ }^{2}$ Department of Endocrinology, Holycross Cancer Centre, Kielce, Poland \\ ${ }^{3}$ Faculty of Medicine and Health Sciences, Jan Kochanowski University, Kielce, Poland
}

Key words: pheochromocytoma; pregnancy; MEN2A syndrome; gestational hypertension

\section{Introduction}

Pheochromocytomas are rare, mostly benign tumours arising from chromaffin cells of the adrenal medulla or many extra-adrenal locations (where they are called paragangliomas). They constitute $7 \%$ (1.5-14\%) of all adrenal incidentalomas [1] and are extremely rare in pregnant women, with a prevalence of 1 in 54,000 pregnancies [2]. The diagnosis is a demanding challenge because the clinical picture ranges from asymptomatic cases to life-threatening hypertensive crises. The disease poses a serious risk to both the mother and the foetus, with a mortality rate of $40-50 \%$ in untreated cases [3]. Therefore, developing a systematic, individualised approach by a multidisciplinary team is crucial for the management of the disease and its consequences.

In this paper, we describe two cases of pheochromocytoma in pregnant women and provide insight into possible dissimilarities in diagnosis, management, and treatment of the disease.

\section{Case no. 1}

A 29-year-old pregnant woman at nine weeks of menstrual age, with recently diagnosed multiple endocrine neoplasia type 2A (MEN2A) syndrome presented herself to the endocrinology outpatient clinic with no symptoms. Blood pressure was 130/80 mm Hg with regular heart rate of $80 \mathrm{bpm}$. Ultrasound revealed multiple hypoechogenic thyroid nodules and right adrenal hypoechogenic mass (15 $\mathrm{mm}$ in diameter). During further diagnostics in the Endocrinology Department, the patient remained asymptomatic and normotensive. Urinary catecholamine metabolites were elevated (Tab. I). Magnetic resonance imaging (MRI) revealed lesions in both adrenal glands (Fig. 1A). Moreover,
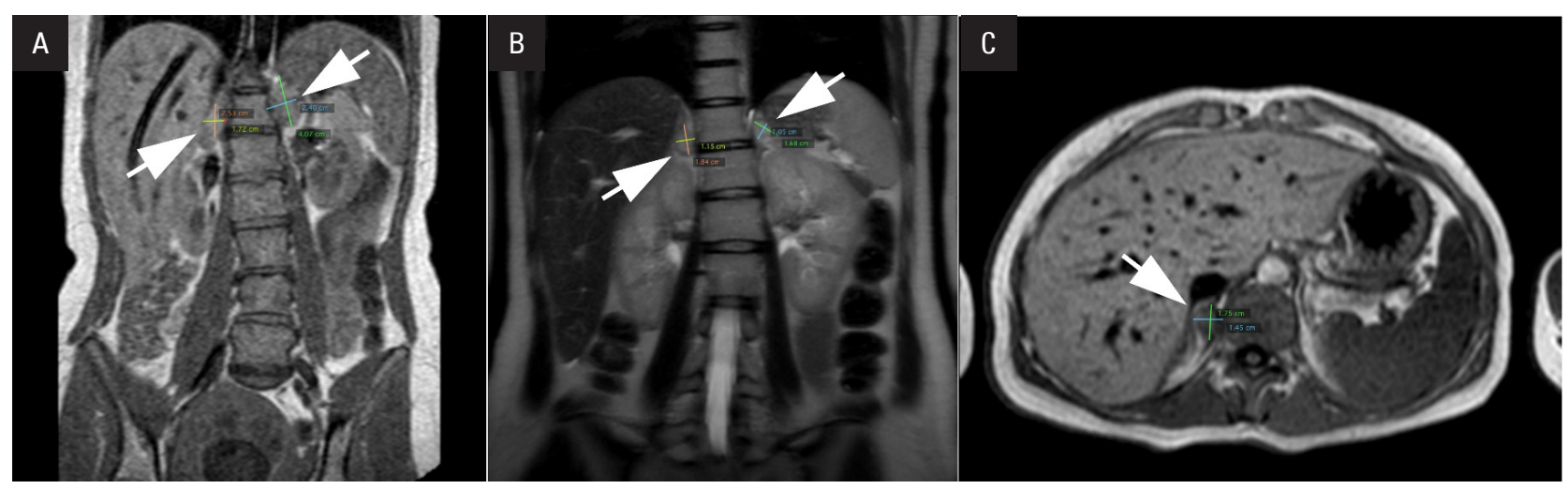

Figure 1. Magnetic resonance imaging of the abdomen without gadolinium. A. Case no. 1: A $40 \times 24$ mm heterogenous mass in the left adrenal gland and a $25 \times 17 \mathrm{~mm}$, mostly homogenous mass in the right adrenal gland; B. Case no. 2.: A $18 \times 12 \mathrm{~mm}$ lesion with moderately high signal intensity in T2-weighted imaging in the right adrenal gland. In the left adrenal gland, a $17 \times 11 \mathrm{~mm}$ mass is present, with similarly increased T2 signal. C. Case no. 2. A $18 \times 15 \mathrm{~mm}$ mass in the right adrenal gland

Grzegorz Chmielewski, Faculty of Medicine and Health Sciences, Jan Kochanowski University, IX Wieków Kielc Av. 19, 25-317, Kielce, Poland, tel: (+48) 512128 787, fax: (+48) 413674 281; e-mail: grzegorz.chmielewski1@gmail.com 
Table 1. Urinary catecholamine metabolites in two cases of pregnant women before and after adrenalectomy

\begin{tabular}{lccccc}
\hline & \multirow{2}{*}{$\begin{array}{c}\text { Normal } \\
\text { value }\end{array}$} & \multicolumn{2}{c}{ Case no. 1 } & \multicolumn{2}{c}{ Case no. 2 } \\
\cline { 3 - 6 } & Before & After & Before & After \\
\hline NMN $[\mu \mathrm{g} / 24 \mathrm{~h}]$ & $88-440$ & 1137.6 & 178.1 & 583.2 & 325.1 \\
\hline MN $[\mu \mathrm{g} / 24 \mathrm{~h}]$ & $52-341$ & 1654.6 & $\begin{array}{c}\text { Undete- } \\
\text { ctable }\end{array}$ & 564.7 & 305.7 \\
\hline 3-MT $[\mu \mathrm{g} / 24 \mathrm{~h}]$ & $0-220$ & 163.2 & 59.9 & 144.9 & 148.9 \\
\hline
\end{tabular}

NMN — normetanephrine; MN — metanephrine; 3-MT - 3-methoxytyramine

fine needle biopsy of thyroid nodules was performed, with a histological image corresponding to medullary cancer. The patient did not consent to any surgical procedure during pregnancy, so adrenalectomy and thyroidectomy were postponed until after delivery. Conservative treatment with $\alpha$ - and $\beta$-blockers (doxazosin, propranolol) was started. Due to risk of preterm delivery, caesarean section was performed in the $33^{\text {rd }}$ week of pregnancy. Preoperatively, a high risk of hypertensive crisis was recognised, but eventually her blood pressure of 170/100 was lowered and stabilised with alpha-blockers and $\beta$-blockers. The rest of the delivery was uneventful. Six weeks later, the patient underwent successful laparoscopic bilateral adrenalectomy. In the pathology report, bilateral pheochromocytomas were confirmed. Six weeks after that, total thyroidectomy was performed. During follow-up, urinary catecholamine metabolites (Tab. 1) and blood pressure were normal. Recovery was satisfactory, the patient remains under regular surveillance in our Department due to MEN2A syndrome.

\section{Case no. 2}

A 29-year-old woman with history of MEN 2A syndrome, medullary thyroid cancer, and primary hyperparathyroidism. Elevated urinary catecholamine metabolites were discovered during a routine follow-up (Tab. I). The patient reported "paroxysmal fatigue". On examination, blood pressure was 105/70 $\mathrm{mm} \mathrm{Hg}$ and heart rate was regular at $68 \mathrm{bpm}$. MRI was performed, revealing two lesions in the right adrenal gland and one in the left adrenal gland (Fig. 1B and 1C). Combined results were suggestive of bilateral pheochromocytomas. Adrenalectomy was planned, but due to the discovery of early pregnancy $\left(10^{\text {th }}\right.$ week $)$, the procedure was postponed until the second trimester. Conservative treatment with doxazosin was initiated. In the $21^{\text {st }}$ week of pregnancy, a right-side open adrenalectomy was performed. Perioperatively, doxazosin was used to prevent blood pressure spikes. The decision was made to keep the left adrenal gland under observation. In the pathology report, two pheochromocytomas were identified. The rest of the pregnancy and the delivery were uneventful. During follow-up, no significant rises in urinary catecholamine metabolites (Tab. 1) or blood pressure were observed. After that, the patient stopped reporting to our department.

\section{Discussion}

Pheochromocytoma in pregnancy is a rare and complex condition. Sustained hypertension or hypertensive crises are dangerous to the mother; moreover, vasoconstriction in the uteroplacental circulation caused by excess catecholamines can lead to intrauterine hypoxia and placental abruption [4]. Despite the rarity of such a diagnosis, physicians should be aware of pheochromocytoma as one of the possible causes of gestational hypertension [5]. As our cases prove, caution should be taken when examining even the asymptomatic patients with germline mutations associated with this tumour. Hereditary pheochromocytoma constitutes around $30 \%$ of all cases [3].

Surgery is the treatment of choice, with the laparoscopic approach being the preferred one nowadays [4]. The second trimester is considered to be optimal because the organogenesis of the foetus is already complete and the pregnant uterus does not block the view as much as it would in the third trimester [3]. Conservative and perioperative treatments consist of an $\alpha$-blocker and an optional $\beta$-blocker $[3,4]$.

No standardised guidelines for treatment of pheochromocytoma in pregnancy have been established, which forces clinicians to rely on their own experience. Early diagnosis and appropriate treatment, with correctly timed surgery being the method of choice, are the keys to keeping both the mother and the foetus safe.

\section{Conflict of interest}

None declared.

\section{References}

1. Lee JM, Kim MK, Ko SH, et. al. Clinical Guidelines for the Management of Adrenal Incidentaloma. Endocrinol Metab. 2017; 32: 200-218. doi: 10.3803/EnM.2017.32.2.200, indexed in Pubmed: 28685511.

2. Mohamed Ismail NA, Abd Rahman R, Abd Wahab N, et. al. Pheochromocytoma and pregnancy: a difficult and dangerous ordeal. Malays J Med Sci. 2012; 19: 65-68. Indexed in Pubmed: 22977377.

3. van der Weerd K, van Noord C, Loeve M, et. al. Pheochromocytoma in pregnancy: case series and review of literature. Eur J Endocrinol. 2017; 177: R49-R58. doi: 10.1530/EJE-16-0920, indexed in Pubmed: 28381449.

4. Lenders JWM. Pheochromocytoma and pregnancy: a deceptive connection. Eur J Endocrinol. 2012; 166: 143-150. doi: 10.1530/EJE-11-0528, indexed in Pubmed: 21890650.

5. Malha L, August P. Secondary Hypertension in Pregnancy. Curr Hypertens Rep. 2015; 17: 53. doi: 10.1007/s11906-015-0563-z, indexed in Pubmed: 26068655. 